observed on most days of the year, usually appearing within an hour after ground sunrise and disappearing during the hour before sunset. On a few occasions each month echoes persist throughout the night. The maximum frequency at which echoes are received usually increases from less than $2 \mathrm{Mc}$./s. at first appearance to greater than $7.5 \mathrm{Mc}$./s. at noon and falling to less than $2 \mathrm{Mc}$./s. at disappearance. Strong $D$-echoes remain on occasions when, due to high absorption, no echoes are received from the normal daytime-occurring ionospheric regions.

As the only factor common to the five stations under discussion is that four are islands and the fifth is sited on a headland with sea on both sides, it appears possible that the effect may be peculiar to island observatories.

Antarctic Division,

G. MAJOR

Department of External Affairs, Melbourne.

Dec. 29.

${ }^{1}$ Ellyett, C. D., Terr. Mag., 52, 1 (1947).

${ }^{2}$ Beagley, J. W., N.Z. J. Sci. and Tech., B, 35 (1953).

\section{Meaning of Turnover in Biochemistry}

Is a recent communication, Kleiber ${ }^{1}$ criticized the 'logic' of the term 'turnover-rate' used as an index of rate of synthesis, exchange, or appearance of some material2. He suggested that turnover-rate should properly refer only to the reciprocal of turnover time, that is, the fraction of a given metabolic pool renewed per unit of time.

Hevesy was among the first to investigate the quantitative aspects of isotope kinetics. He employed the term turnover-rate to denote the amount of material transferred per unit of time ${ }^{3}$. Many others have followed this usage ${ }^{4-6}$. An investigator may measure the rate of a metabolic process in terms of the fraction of the total metabolic pool renewed per hour; but it would be less confusing to designate this quantity by a term other than 'turnover-rate'. Kleiber ${ }^{1}$ assumes that the use of 'turnover' in metabolic work arises from the analogy with the turnover of a wheel. However, this assumption may be unwarranted, for the early workers in the isotope field may have employed the analogy with the rapid turnover of patients in a well-organized hospital or the labour turnover-rate of an organization. This quantity may be expressed in terms of absolute turnover-rate (that is, the number of men entering or leaving the group), or as relative turnoverrate (the ratio of the absolute turnover-rate to the average working-force). Thus, there seems to be no a priori reason why the use of 'turnover-rate' should be restricted to the latter sense when dealing with metabolic processes. In our own work we have differentiated between (absolute) turnover-rates and fractional turnover-rates ${ }^{7}$. Reiner ${ }^{6}$ has used relative turnover-rate for the latter. Considerable confusion may be anticipated if various investigators attach different definitions to standard terms.

In recognition of the importance of a clear-cut terminology in this field, and in keeping with present-day usage, I wish to propose the following definitions:

Turnover-rate. The quantity of material turned over per unit of time.
Fractional turnover-rate. The fraction of a given pool turned over per unit of time.

Turnover-time. The time required for the turnover of an amount of material equal to the pool size; this is the reciprocal of the fractional turnover-rate.

\section{B. Zilversmit}

Department of Physiology,

University of Tennessee,

Memphis 3, Tennessee. March 19.

1 Kleiber, M., Nature, 175, 342 (1955).

Z Zilversmit, D. B., Entenman, C., and Fishler, M. C., J. Gen. Physiol. 26, 325 (1943).

${ }^{8}$ Hevesy, G. "Radioactive Indicators", 251 (Interscience Publishers, New York, 1948).

- Kamen, M. D. “Radioactive Tracers in Biology", 135 (Acad. Press, New York, 1951).

s Sacks, J., "Ysotopic Tracers in Biochemistry and Physiology", 78 (McGraw-Hill, New York, 1953).

- Reiner, J. M., Arch. Biochem. and Biophys., 46, 53 (1953).

'Di Luzio, N. R., and Zilversmit, D. B., Amer. J. Physiol., 170, 472 (1952).

\section{Paper Chromatography of Inositol Phosphates}

IN the course of an examination of the organic phosphorus compounds in soils, a fraction was isolated rich in a substance resembling phytic acid, and which on hydrolysis yielded meso-inositol. Since lower phosphate esters of inositol may be present in soil, a chromatographic study has been carried out on the products obtained on partial hydrolysis of authentic phytin by acid, or by an enzyme method described. by $\mathrm{S}$. and T. Posternak ${ }^{1}$.

Of the many solvent systems investigated, the best had the composition : 70 vols. methanol $/ 30$ vols. $0.5 \mathrm{~N}$ ammonium hydroxide. The hydrolysate was best applied in a small band to the paper, which had previously been washed thoroughly with dilute hydrochloric acid, water, ammonium versenate and water, in that order. Upward development was carried out at about $23^{\circ} \mathrm{C}$., but the temperature was not rigidly controlled. Spots were detected by spraying with the molybdate-perchloric acid reagent of Hanes and Isherwood ${ }^{2}$, and heating the papers between glass plates in an oven at $90^{\circ} \mathrm{C}$. for $30 \mathrm{~min}$.

Four spots were obtained from the hydrolysates, with the following $R_{F}$ values:

$\begin{array}{lc} & R F \\ \text { (1) Inositol hexaphosphate } & 0 \cdot 06 \\ \text { (2) First intermediate ester(s) } & 0 \cdot 17 \\ \text { (3) Second intermediate ester(s) } & 0 \cdot 32 \\ \text { (4) Orthophosphate (+ probable third intermediate) } & 0 \cdot 48\end{array}$

Resolution between the lowest two spots was not always absolute, depending upon the relative amounts of the two constituents present, but a clear demarca. tion could always be drawn between them. The spot with $R_{F}$ value $0 \cdot 17$ is most likely to be the tetraphosphate, but work is being continued to establish the identity of the intermediates. There is evidence of a third intermediate, masked by the orthophosphate, and present in only very small amount even at advanced stages of hydrolysis.

Several inositol phosphates have been isolated by large-scale fractionation of phytic acid hydrolysates $^{1,3,4}$; but no paper chromatographic method of separation appears to have been published. The 